\title{
Intrinsic Radiation Resistance of Primary Clonogenic Blasts from Children with Newly Diagnosed B-Cell Precursor Acute Lymphoblastic Leukemia
}

\author{
Fatih M. Uckun, ${ }^{\star \star \|}$ Waclaw Jaszcz, ${ }^{3}$ Mridula Chandan-Langlie, ${ }^{\star}$ Kevin G. Waddick, ${ }^{\star}$ \\ Kazimiera Gajl-Peczalska, and Chang W. Song* \\ *Tumor Immunology Laboratory, Sections of Cancer and Leukemia Biology and Radiation Biology, Department of Therapeutic \\ Radiology-Radiation Oncology, ${ }^{\ddagger}$ Division of Hematology/Oncology/Bone Marrow Transplantation Program, Department of Pediatrics, \\ ${ }^{\S}$ Department of Laboratory Medicine/Pathology, University of Minnesota Health Sciences Center, Minneapolis, Minnesota 55455; and \\ "The Children's Cancer Study Group, Arcadia, California 91066
}

\begin{abstract}
The radiation sensitivity of primary clonogenic blasts from 44 children with newly diagnosed B-cell precursor acute lymphoblastic leukemia (ALL) was analyzed using leukemic progenitor cell (LPC) colony assays. The derived values for $\mathrm{SF}_{2}$ (surviving fraction at $200 \mathrm{cGy}$ ) and $\alpha$ (initial slope of radiation survival curves constructed according to the linear quadratic model) indicated a marked interpatient heterogeneity in intrinsic radiation sensitivity of $\mathrm{LPC}$ populations. The $\mathrm{SF}_{2}$ values ranged from 0.01 to 1.00 (median $=0.430$; mean \pm SE $=0.47 \pm 0.04$ ), and the $\alpha$ values ranged from 0.000 to 3.272 $\mathrm{Gy}^{-1}\left(\right.$ median $=0.280 \mathrm{~Gy}^{-1} ;$ mean $\left.\pm \mathrm{SE}=0.430 \pm 0.093 \mathrm{~Gy}^{-1}\right)$. When $\mathrm{CD19}^{+} \mathrm{CD34}^{+}$versus $\mathrm{CD}^{+}{ }^{+} \mathrm{CD34}^{-}$immunophenotypes were compared, a trend toward higher $\mathrm{SF}_{2}$ and lower $\alpha$ values were observed in $\mathrm{LPC}$ from $\mathrm{CD34}^{+}$patients, consistent with greater radiation resistance. When patients were divided into three approximately equal groups based on increasing levels of CD34 expression, a clear ordering effect was observed indicating that increased CD34 expression levels are associated with significantly higher radiation resistance at the level of $B$ lineage LPC. The highest CD34 expression group ( $\geq 75 \%$ positivity) had 1.4-fold higher $\mathrm{SF}_{2}(P=0.05)$ and twofold lower $\alpha$ values $(P=0.06)$ than the lowest group ( $<30 \%$ positivity). Furthermore, the CD34 positivity of radiation resistant ( $\alpha$ $\leq 0.2$ and $\left.\mathrm{SF}_{2} \geq 0.5\right)$ B-cell precursor $\mathrm{ALL}$ cases was greater than the CD34 positivity of radiation sensitive $(\alpha>0.2$ and /or $\left.\mathrm{SF}_{2}<0.5\right)$ cases $(56 \pm 9 \%$ versus $34 \pm 9 \%, P=0.09)$. Whereas only 6 of $16(38 \%)$ of radiation sensitive cases were $\mathrm{CD}_{34}^{+}, 11$ of $15(73 \%)$ of radiation resistant cases expressed CD34 ( $P$ $=0.04)$. Our results offer new insights into the inherent and / or acquired radiation resistance of primary clonogenic blasts from B-cell precursor ALL patients. (J. Clin. Invest. 1993. 91:1044-1051.) Key words: immunophenotype • leukemia • radiation resistance • clonogenic cells • leukemic progenitor cell

\section{Introduction}

High risk acute lymphoblastic leukemia (ALL) ${ }^{1}$ patients typically suffer a poor outcome after conventional drug treatment

Address correspondence to Fatih M. Uckun, M.D., Ph.D., Box 356 UMHC, Section of Cancer and Leukemia Biology, University of Minnesota, 420 Delaware St., Minneapolis, MN 55455.

Received for publication 12 August 1992 and in revised form 13 October 1992.

1. Abbreviations used in this paper: ALL, acute lymphoblastic leukemia; BMT, bone marrow transplantation; L-BCGF, low molecular

J. Clin. Invest.

(C) The American Society for Clinical Investigation, Inc.

0021-9738/93/03/1044/08 \$2.00

Volume 91, March 1993, 1044-1051 protocols (1). Within the last decade, however, total body irradiation (TBI) and high dose chemotherapy have been applied before bone marrow transplantation (BMT) in aggressive regimens to enhance these patients' prospects for disease-free survival (2-9). Although improvements in long-term, disease-free survival have been reported, recurrence of leukemia within the first 6 mo after TBI and BMT continues to be a major obstacle to a more successful outcome after BMT for high risk ALL, and only $<20 \%$ of high risk ALL patients become long-term, disease-free survivors after autologous or allogeneic BMT (2-13). The inability of TBI to adequately destroy leukemia cells and prevent residual disease may involve several possibilities. Clonogenic blasts (i.e., leukemic progenitor cells [LPC] may $(a)$ possess an intrinsic resistance to radiation; $(b)$ contain a large fraction of noncycling dormant blasts; $(c)$ effectively repair sublethal radiation injury; $(d)$ be capable of rapid self-renewal and repopulation; and / or $(e)$ survive in quantities sufficient to cause relapse as a result of a high leukemia burden at remission.

Until we learn more about the effects of TBI on LPC, the results of radiation based pre-BMT conditioning regimens are not likely to dramatically improve. A thorough radiobiologic analysis of primary clonogenic blasts from ALL patients is a requisite step toward greater understanding of clinical radiation resistance. The present study initiated this task by evaluating the radiation sensitivity of primary clonogenic blasts from 44 newly diagnosed B-cell precursor ALL patients. Two computer-based models of cell survival were used (14). The multitarget model of survival curve analysis (14-16) provides $\mathrm{SF}_{2}$ values as parameters to describe intrinsic radiation sensitivity. The surviving fraction at $200 \mathrm{cGy}\left(\mathrm{SF}_{2}\right)$ value is the surviving fraction of clonogenic blasts after exposure to $200 \mathrm{cGy}$. The major parameter for intrinsic radiation sensitivity in the linear quadratic model (14-16) is the $\alpha$ value, representing the initial slope of the linear component of the continuously bending radiation dose survival curve. Clonogenic blasts are considered sensitive to radiation based on high $\alpha$ values and low $\mathrm{SF}_{2}$ values.

We initially recorded a marked interpatient variation in the values obtained from survival curves generated by LPC. Clonogenic blasts from different B-cell precursor ALL patients varied substantially in their sensitivity to radiation. We examined possible relationships between LPC radiation responses and the standard diagnostic features of these patients, including age, sex, white blood cell count (WBC) at diagnosis, immunophenotype, and cell cycle distribution of bone marrow blasts. Our observations indicated that LPC are intrinsically more resistant to radiation when a high percentage of blasts are in the $G_{0 / 1}$

weight B-cell growth factor; LPC, leukemic progenitor cells; PKC, protein kinase $\mathrm{C} ; \mathrm{SF}_{2}$, surviving fraction at $200 \mathrm{cGy}$; WBC, white blood cell count. 
phases of the cell cycle or a low percentage of blasts are in the $S$ phase. Further results provided evidence that radiation resistance may be associated with a high level of CD34 antigen expression. To our knowledge, this report represents the first radiobiologic analysis comparing radiation responses of primary LPC in relation to diagnostic features that distinguish B-cell precursor ALL patients.

\section{Methods}

Patient selection and patient material. Fresh leukemic bone marrow samples from 44 newly diagnosed B-cell precursor ALL patients were used to study the radiobiologic features of primary clonogenic blast populations. Diagnosis of B-cell precursor ALL was based on the morphologic, cytochemical, and immunophenotypic features of marrow blasts. There were 17 females and 27 males with a median age of $4 \mathrm{yr}$ (range: $0.1-17 \mathrm{yr} ;$ mean $\pm \mathrm{SE}=5.5 \pm 0.7 \mathrm{yr} ; n=44$ ). 37 of 44 patients $(84 \%)$ were $<10 \mathrm{yr}$ of age. The initial WBC ranged from $4.0 \times 10^{9}$ to $999.0 \times 10^{9} /$ liter $\left(\right.$ median $=74.0 \times 10^{9} /$ liter; mean \pm SE $=138.1 \pm 33.6 \times 10^{9} /$ liter $\left.; n=34\right)$. The cell cycle distribution of leukemic blasts was evaluated by DNA flow cytometry in a total of 18 patients. The percentage of $\mathrm{G}_{0 / 1}$ phase cells ranged from 72 to $95 \%$ (median- $85 \%$; mean $\pm \mathrm{SE}=85 \pm 1 \%)$. The percentage of $\mathrm{S}$ phase cells ranged from 4 to $23 \%$ (median $=13 \%$; mean $\pm \mathrm{SE}=12 \pm 1 \%)$ and the proliferation index ( $\mathrm{PI}=\% \mathrm{~S}+\% \mathrm{G}_{2} \mathrm{M}$ ) ranged from 5 to $28 \%$ (median $=15 \% ;$ mean $\pm \mathrm{SE}=15 \pm 1 \%)$.

The immunophenotypic features of leukemic blasts were determined by immunofluorescence staining and flow cytometry using a broad panel of $\mathrm{mAb}$ reactive with lymphoid differentiation antigens. None of 44 patients expressed the pan-T cell antigens CD2, CD5, and $\mathrm{CD} 7$ or the mature B-cell marker surface immunoglobulin. In contrast, leukemic blasts from each of the 44 patients expressed high levels of CD19 and/or CD24 B-lineage differentiation antigens. $89 \pm 1 \%$ of leukemic blasts from 44 of 44 ( $100 \%$ ) expressed CD19, $83 \pm 3 \%$ of leukemic blasts from 34 of 40 patients ( $85 \%$ ) expressed CD24, and $57 \pm 4 \%$ of leukemic blasts from 10 of 28 patients ( $36 \%$ ) expressed CD40 antigen. The lymphoid precursor cell antigen CD10 was expressed on $82 \pm 3 \%$ of leukemic blasts from 33 of $44(75 \%)$ patients. The progenitor cell associated antigen CD34 was expressed on $76 \pm 5 \%$ of leukemic blasts from 17 of 31 patients $(55 \%)$. Thus, leukemic blasts displayed a common composite immunophenotype $\left(\mathrm{CD}^{-} \mathrm{CD}^{-} \mathrm{CD} 7^{-} \mathrm{CD} 10^{+/-} \mathrm{CD} 19^{+}\right.$ $\mathrm{CD} 24^{+} \mathrm{CD} 34^{+/-} \mathrm{CD}{ }^{+/-} \mathrm{sIg}^{-}$) consistent with B-cell precursor ALL. Fresh bone marrow aspirates were procured by conventional methods as part of clinical treatment protocols. Mononuclear cells highly enriched for leukemic blasts (i.e., containing > 90\% blasts) were isolated from fresh bone marrow aspirates by density gradient separation on Ficoll-Hypaque gradients. All patient bone marrow samples were used following the guidelines of the University of Minnesota Committee on the Use of Human Subjects in Research for secondary use of pathologic or surgical tissue.

Immunophenotyping. The surface antigen profiles of freshly isolated B-cell precursor ALL blasts were analyzed by indirect immunofluorescence and flow cytometry using a panel of monoclonal antibodies $(\mathrm{mAb})$ that define human leukocyte differentiation antigens as previously described (17-20). Specifically, we used the mAbs $13-\mathrm{B} 3 / 35.1$ (anti-CD2), T101/10.2 (anti-CD5), G3.7 (anti-CD7), BA-3 (antiCD10), B43 (anti-CD19), BA-1 (anti-CD24), MY10 (anti-CD34), and G28-5 (anti-CD40). Samples were considered positive if $>30 \%$ of cells bound the antibody used.

Analysis of cell cycle kinetics by quantitative DNA flow cytometry. DNA content and cell cycle distribution of leukemic marrow blasts were evaluated by flow cytometric DNA analysis of fixed cells stained with propidium iodide (Sigma Chemical Co., St. Louis, MO) after treatment with RNAse $(21,22)$. Flow cytometric data of at least 20,000 cells from each sample were acquired in linear mode using a flow cytometer (FACScan ${ }^{\circledR}$; Becton Dickinson, Mountain View, CA). Data were analyzed using polynomial and broadened rectangle models of DNA-ploidy-cell cycle and software (DNA Cell-Cycle Analysis Software; Becton Dickinson).

Irradiation of cells. Primary B-cell precursor ALL blasts, $1 \times 10^{5}$ cells $/ \mathrm{ml}$ in alpha-MEM supplemented with $5 \%$ FCS, were irradiated with 50-800 cGy gamma rays in a single exposure ( $100 \mathrm{cGy} / \mathrm{min}$, $37^{\circ} \mathrm{C}$ ) using a ${ }^{137} \mathrm{Cs}$ irradiator (model Mark I; J. L. Shephard and Associates, Glendale, CA), as previously described (22-25). After irradiation, $1 \times 10^{5} \mathrm{ALL}$ blasts per sample were assayed in duplicate for LPC-derived B-cell precursor ALL blast colony formation, as described in the next paragraph. The surviving fractions of clonogenic blasts were determined using the formula: Percent survival $=100 \times($ mean number of colonies in irradiated samples)/(mean number of colonies in unirradiated control samples). The radiation survival curves were constructed using computer programs for the analysis of cell survival data according to the single-hit multitarget and linear quadratic models, as detailed under Data analysis hereinafter. Data were expressed as the mean $\pm \mathrm{SE}$ values for $\mathrm{SF}_{2}$ as well as the $\alpha$ (initial slope reflecting the steepness of the linear component of cell killing) value of the linear quadratic model.

Colony assays for primary clonogenic blasts from B-cell precursor ALL patients. A small fraction of leukemic B-cell precursors from ALL patients proliferate in response to low molecular weight B-cell growth factor (L-BCGF; Cellular Products, Buffalo, NY) and form compact blast colonies $(20,25,26,27)$. Day 7 ALL blast colonies are very compact and have a small size containing 20-50 lymphoblasts (20, 27 ). Therefore, colony numbers up to 3,000 per Petri dish can easily be enumerated on a grid using an inverted phase microscope of high optical resolution $(20,27)$. In the present study, fresh ALL marrow blasts $\left(1 \times 10^{5}\right.$ blasts $/ \mathrm{ml}$, duplicate $\left.1-\mathrm{ml} \mathrm{samples}\right)$ were irradiated and immediately plated in $35-\mathrm{mm}$ Petri dishes for a $7-\mathrm{d}$ culture at $37^{\circ} \mathrm{C}$ in a humidified $5 \% \mathrm{CO}_{2}$ atmosphere in alpha-MEM. Medium was supplemented with $0.9 \%$ methylcellulose, $50 \mu \mathrm{M}$ 2-mercaptoethanol, $15 \%$ human plasma $+15 \%$ fetal bovine serum (or $30 \%$ calf bovine serum), and $10 \%(\mathrm{vol} / \mathrm{vol})$ L-BCGF $(20,25-27)$. On day 7 , blast colonies containing $>20$ cells were counted using an inverted phase microscope with high optical resolution. After the enumeration of colonies in each petri dish, colony blasts were subjected to morphological and immunological analyses, as described $(20,25-30)$. In all experiments, culture dishes were examined immediately and $24 \mathrm{~h}$ after plating to exclude the possibility of clumping unrelated to proliferation, which might lead to wrong conclusions regarding the radiation sensitivity of clonogenic blasts.

Data analysis. The radiation survival curves were constructed using three computer programs for the MacIntosh, ENTER, DSUM, and FIT (kindly provided by Dr. N. Albright, Department of Radiation Oncology, University of California, San Francisco, CA), for the analysis of cell survival data according to the single-hit multitarget and linear quadratic models of cell survival $(14,22)$. The data in this study were expressed as $\mathrm{SF}_{2}$ value representing the radiation sensitivity parameter of the single-hit multitarget model of cell survival, as well as the $\alpha$ value representing the radiation sensitivity parameter of the linear quadratic model of cell survival $(14,22)$. We used standard statistical methods, including Student's $t$ tests, to evaluate the in vitro radiation survival data and to compare the radiobiologic features of primary clonogenic blasts from different patients, as previously described $(22,25)$. Chi square analyses were used to assess the degree of association between clinical/laboratory parameters and radiation resistance/sensitivity of LPC. All computations were performed using an updated statistics program for the MacIntosh (StatWorks; Cricket Software, Philadelphia, PA).

\section{Results}

Radiobiologic features of primary clonogenic blasts from newly diagnosed B-lineage ALL patients. Primary bone marrow blasts from 44 patients were exposed to ionizing radiation, cultured in the presence of L-BCGF, and assayed for LPC-derived 


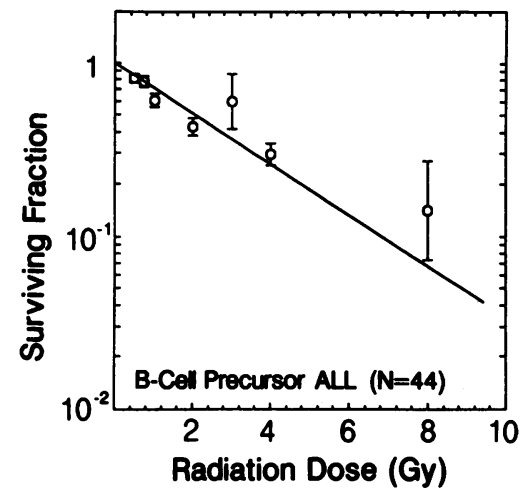

Figure 1. Composite radiation survival curve of primary clonogenic blasts from newly diagnosed B-cell precursor ALL patients. Survival of primary clonogenic blasts from 44 newly diagnosed B-cell precursor ALL patients is shown as a function of the radiation dose. Cells were irradiated, assayed for blast colony formation in vitro, and the composite radiation survival curve was generated using a computer program according to the linear quadratic model of cell survival as described in Methods. The calculated standard errors are also indicated. Each independent experiment was performed in duplicate.

blast colony formation. The median and mean numbers of blast colonies in unirradiated control cultures were 1,097 colonies $/ 10^{5}$ cells ( $1.1 \%$ plating efficiency) and $1,668 \pm 217$ colonies $/ 10^{5}$ cells ( $1.7 \pm 0.2 \%$ plating efficiency), respectively.

Radiation survival curves of primary clonogenic blasts (i.e., LPC) were constructed for each of the 44 newly diagnosed
B-cell precursor ALL patients using computer programs for the single-hit multitarget, as well as the linear quadratic models of cell survival. The computer-determined values for the radiobiologic parameters indicated a marked interpatient heterogeneity in intrinsic radiation sensitivity of LPC populations. The $\mathrm{SF}_{2}$ values ranged from 0.01 to 1.00 (median $=0.430$; mean $\pm \mathrm{SE}=0.47 \pm 0.04$ ), and the $\alpha$ values ranged from 0.000 to $3.272 \mathrm{~Gy}^{-1}$ (median $=0.280 \mathrm{~Gy}^{-1}$; mean $\pm \mathrm{SE}$ $\left.=0.430 \pm 0.093 \mathrm{~Gy}^{-1}\right)$. The $\mathrm{SF}_{2}$, and $\alpha$ values of the composite radiation survival curve were 0.42 and $0.337 \mathrm{~Gy}^{-1}$, respectively (Fig. 1). LPC from 17 of 44 patients (39\%) had $\mathrm{SF}_{2}$ values $\geq 0.50$ and $\alpha$ values $\leq 0.2 \mathrm{~Gy}^{-1}$, consistent with a marked radiation resistance at the level of LPC using the multitarget and linear quadratic models of cell survival. The mean $\mathrm{SF}_{2}$ value for this subgroup of 17 patients was $0.75 \pm 0.04$, which is significantly higher than the mean $\mathrm{SF}_{2}$ value of $0.29 \pm 0.03$ for the remaining 27 radiation sensitive patients $(P$ $<0.0001$ ). The mean $\alpha$ values were $0.063 \pm 0.016 \mathrm{~Gy}^{-1}$ for the radiation resistant group $(n=17)$ and $0.660 \pm 0.133 \mathrm{~Gy}^{-1}$ for the radiation sensitive group $(n=27)(P<0.0001)$.

Correlation between radiobiologic features of primary $B-$ lineage LPC and patients' characteristics. Patients were divided into groups according to sex, age, WBC at diagnosis, cell cycle distribution of leukemic blasts, and immunophenotype (Table I). Patients with a high percentage of blasts in $\mathrm{G}_{0 / 1}$

Table I. Statistical Correlations

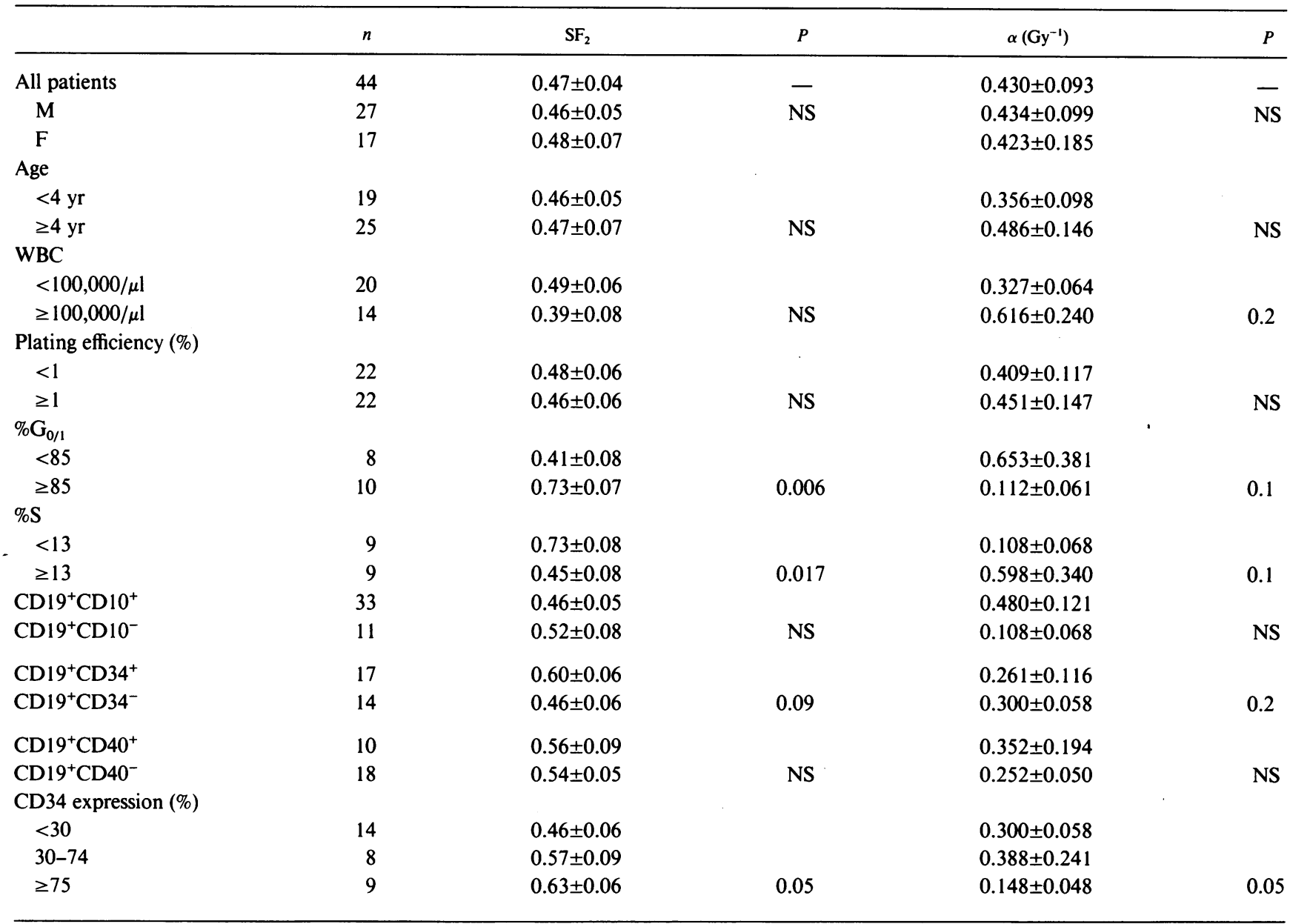

The $\mathrm{SF}_{2}$ and $\alpha$ values (mean $\pm \mathrm{SE}$ ) of B-lineage LPC from newly diagnosed B-cell precursor ALL patients were compared using two sample, twosided Student's $t$ tests. 
phases of the cell cycle or a low percentage of blasts in $\mathrm{S}$ phase had higher $\mathrm{SF}_{2}$ and smaller $\alpha$ values, consistent with a higher intrinsic radiation resistance at the level of LPC (Table I, Fig. 2 ). Whereas only $25 \%$ of cases with $\mathrm{G}_{0 / 1}<85 \%$ had $\mathrm{SF}_{2}$ values $\geq 0.5$, consistent with radiation resistance according to single hit multitarget model of cell survival, $80 \%$ of cases with $G_{0 / 1}$ $\geq 85 \%$ had $\mathrm{SF}_{2}$ values $\geq 0.5$ (Fig. 2 ). Similarly, $90 \%$ of cases with $\mathrm{G}_{0 / 1} \geq 85 \%$ versus $37.5 \%$ of cases with $\mathrm{G}_{0 / 1}<85 \%$ had $\alpha$ values $\leq 0.2$, consistent with radiation resistance according to linear quadratic model of cell survival (Fig. 2). Furthermore, univariate analysis using $G_{0 / 1}$ and $S$ phase percentages as continuous covariates established a significant association between $\mathrm{G}_{0 / 1}$, as well as $\mathrm{S}$ phase percentages and $\mathrm{SF}_{2}\left(\% \mathrm{G}_{0 / 1}\right.$ versus $\mathrm{SF}_{2}$ : coefficient of correlation $=0.36, P=0.1 ; \% \mathrm{~S}$ phase versus $\mathrm{SF}_{2}$ : coefficient of correlation $=0.29, P=0.1$ ), as well as $\alpha$ values $\left(\% \mathrm{G}_{0 / 1}\right.$ versus $\alpha$ : coefficient of correlation $=0.29, P=0.1 ; \% \mathrm{~S}$ phase versus $\alpha$ : coefficient of correlation $=0.26, P=0.1)$. In contrast, patient age, WBC, or in vitro plating efficiency as continuous covariates did not correlate with $\mathrm{SF}_{2}$ or $\alpha$ values $(P$ values all $>0.3$ ). Similarly, when patients were divided into groups, patient sex, age, WBC at diagnosis, or in vitro plating efficiency did not have a significant impact on the radiation sensitivity of LPC (Table I).

In our initial analyses of immunophenotype-radiation sensitivity associations, we used antigen expression on $\geq 30 \%$ blasts as an arbitrary criterion for positivity. According to this conventional classification, 17 of 31 patients $(55 \%)$ were $\mathrm{CD} 19^{+} \mathrm{CD} 34^{+}$, and 14 of 31 patients $(45 \%)$ were $\mathrm{CD}_{19}{ }^{+} \mathrm{CD} 34^{-}$. When $\mathrm{CD} 19^{+}-\mathrm{CD} 34^{+}$versus $\mathrm{CD} 19^{+} \mathrm{CD} 34^{-}$patients were compared, a trend towards higher $\mathrm{SF}_{2}$ and lower $\alpha$ values was observed in LPC from CD34 $4^{+}$patients, consistent with greater radiation resistance (Table $\mathrm{I}$ ). By comparison, a trend towards lower $\mathrm{SF}_{2}$ and higher $\alpha$ values was observed for $\mathrm{CD} 19^{+} \mathrm{CD}_{10}{ }^{+}$ patients and $\mathrm{CD} 40$ expression was not associated with radiation resistance or sensitivity of LPC from CD $19^{+}$B-lineage ALL patients (Table I). There were not enough $\mathrm{CD}^{-} 9^{-}$or CD24- patients to examine the potential influence of lack or presence of CD19 or CD24 on LPC radiation sensitivity. To further investigate the influence of $\mathrm{CD} 34$ expression on radiation sensitivity at the level of LPC, patients were divided into three approximately equal groups based on increasing levels of CD34 expression (Table I). A clear ordering effect was observed, indicating that increased CD34 expression levels are
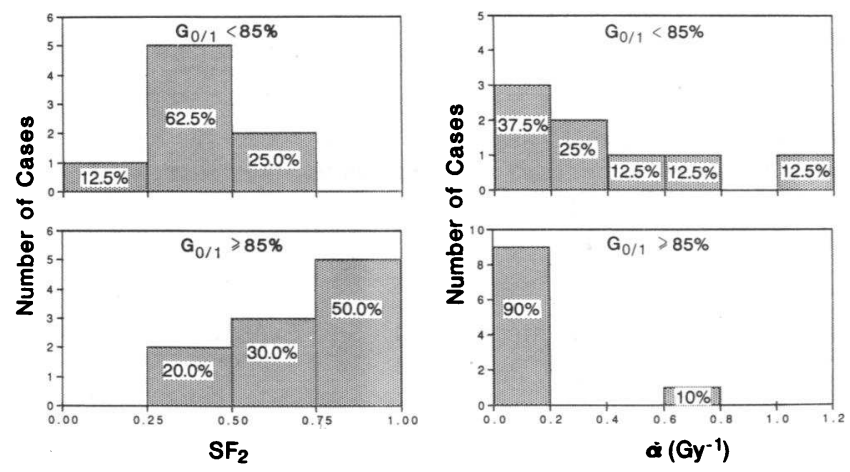

Figure 2. Radiation sensitivity of primary clonogenic blasts from newly diagnosed B-cell precursor ALL patients according to the $G_{0 / 1}$ percentage. The distribution of $\mathrm{SF}_{2}$ and $\alpha$ values is shown for patients with $\mathrm{G}_{0 / 1} \geq 85 \%$ or $\mathrm{G}_{0 / 1}<85 \%$. associated with significantly higher radiation resistance at the level of B-lineage LPC. The highest CD34 expression group ( $\geq 75 \%$ positivity) had 1.4-fold higher $\mathrm{SF}_{2}(P=0.05)$ and twofold lower $\alpha$ values $(P=0.05)$ than the lowest CD34 expression group ( $<30 \%$ positivity). As shown in Fig. 3, increased CD34 expression levels were associated with a higher radiation resistant fraction. Whereas only $35.7 \%$ of $\mathrm{CD}^{-} 4^{-}$cases $(<30 \%$ positivity) had LPC with $\mathrm{SF}_{2} \geq 0.5,62.5 \%$ of patients with intermediate $(<75 \%, \geq 30 \%) \mathrm{CD} 34$ positivity, and $66.6 \%$ of patients with high ( $\geq 75 \%$ ) CD34 positivity had $\mathrm{LPC}$ with $\mathrm{SF}_{2} \geq 0.5\left(\chi^{2}\right.$ $=2.10, P=0.15)$. Similarly, only $35.7 \%$ of CD $34^{-}$cases had $\alpha$ $\leq 0.2$, whereas $62.5 \%$ of cases with intermediate CD34 positivity and $77.8 \%$ of cases with high CD34 positivity had $\alpha \leq 0.2$ $\left(\chi^{2}=3.88, P<0.05\right)$.

Presenting features of $B$-cell precursor ALL patients with radiation-resistant $L P C$. LPC from 17 patients had $\mathrm{SF}_{2}$ values $\geq 0.50$ and $\alpha$ values $\leq 0.2 \mathrm{~Gy}^{-1}$. The radiation resistant group was composed of slightly younger children than the radiationsensitive group. Of 17 radiation-resistant cases, $16(94 \%)$ were children $<10$ yr of age. By comparison, 21 of $27(78 \%)$ radiation sensitive cases were $<10$ yr of age. The mean age was $4.5 \pm 0.8 \mathrm{yr}$ for the radiation resistant group and $6.2 \pm 0.9 \mathrm{yr}$ for the radiation-sensitive group $(P=0.2)$. A trend towards lower WBC values was noted among radiation-resistant cases (Table II). Whereas only $25 \%$ of radiation resistant cases had WBC $>100,000$, some $50 \%$ of radiation-sensitive cases had WBC $>100,000$. The mean $\mathrm{WBC}$ values were $91 \pm 39 \times 10^{9} /$ liter for radiation-resistant cases and $170 \pm 46 \times 10^{9} /$ liter for radiationsensitive cases $(P=0.2)$. The sex distribution of patients with radiation-resistant versus radiation-sensitive LPC were not significantly different (Table II). Notably, a greater fraction of radiation-resistant cases had high $\mathrm{G}_{0 / 1}$ phase percentages $(\geq 85 \%)(80 \%$ versus $25 \%, P=0.02)$ and low $S$ phase percentages ( $<13 \%)(70 \%$ versus $25 \%, P=0.06)$ than radiation sensitive cases (Table II), in accordance with the association between high $\mathrm{G}_{0 / 1}$ phase percentage or low $\mathrm{S}$ phase percentage and radiation resistance shown in Table $I$ and Fig. 3. $70 \%$ of
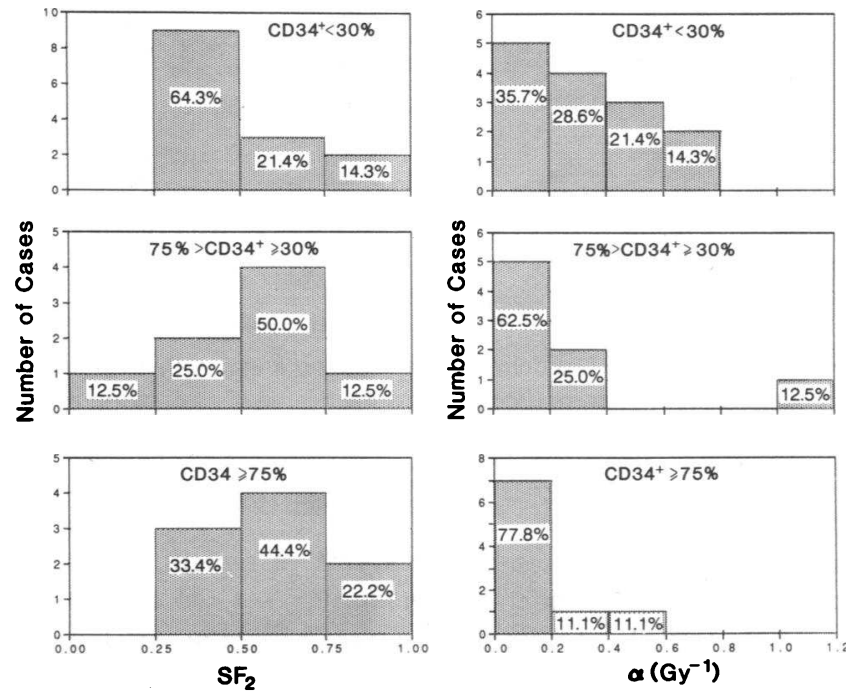

Figure 3. Radiation sensitivity of primary clonogenic blasts from newly diagnosed B-cell precursor ALL patients according to CD34 antigen expression. The distributions of $\mathrm{SF}_{2}$ and $\alpha$ values from $\mathrm{CD} 34^{+}$and $\mathrm{CD}_{4} 4^{-}$patients are compared. 
Table II. Presenting Features of B-Cell Precursor ALL Patients According to Radiation Sensitivity of the LPC

\begin{tabular}{|c|c|c|c|}
\hline & $\begin{array}{l}\text { Radiation resistant LPC } \\
\qquad \begin{array}{l}n=17\end{array}\end{array}$ & $\begin{array}{c}\text { Radiation sensitive LPC } \\
\qquad n=27\end{array}$ & $P$ value \\
\hline $\mathrm{D}_{0}$ value & $353.9 \pm 65.5$ & $216.2 \pm 32.8$ & 0.04 \\
\hline $\mathrm{SF}_{2}$ value & $0.75 \pm 0.04$ & $0.29 \pm 0.03$ & $<0.001$ \\
\hline$\alpha$ Value & $0.063 \pm 0.016$ & $0.660 \pm 0.133$ & $<0.001$ \\
\hline \multicolumn{4}{|l|}{ Sex } \\
\hline Male & $11 / 17(65 \%)$ & $16 / 27(59 \%)$ & \\
\hline Female & $6 / 17(35 \%)$ & $11 / 27(41 \%)$ & \\
\hline \multicolumn{4}{|l|}{ Age } \\
\hline$<10 \mathrm{yr}$ & $16 / 17(94 \%)$ & $21 / 27(78 \%)$ & \\
\hline$\geq 10 \mathrm{yr}$ & $1 / 17(6 \%)$ & $6 / 27(22 \%)$ & \\
\hline Mean \pm SE yr & $4.5 \pm 0.8$ & $6.2 \pm 0.9$ & \\
\hline \multicolumn{4}{|l|}{ WBC } \\
\hline$<100,000 / \mu 1$ & $9 / 12(75 \%)$ & $11 / 22(50 \%)$ & \\
\hline$\geq 100,000 / \mu 1$ & $3 / 12(25 \%)$ & $11 / 22(50 \%)$ & \\
\hline Mean \pm SE $\left(\times 10^{3} / \mu \mathrm{l}\right)$ & $91 \pm 39$ & $170 \pm 46$ & \\
\hline \multicolumn{4}{|l|}{ CD10 } \\
\hline Positive cases & $13 / 17(76 \%)$ & $20 / 27(74 \%)$ & \\
\hline Negative cases & $4 / 17(24 \%)$ & $7 / 27(26 \%)$ & \\
\hline Mean \% positivity & $65 \pm 9$ & $63 \pm 7$ & \\
\hline \multicolumn{4}{|l|}{ CD19 } \\
\hline Positive cases & $17 / 17(100 \%)$ & $27 / 27(100 \%)$ & \\
\hline Negative cases & $0 / 17(0 \%)$ & $0 / 27(0 \%)$ & \\
\hline Mean $\%$ positivity & $90 \pm 2$ & $88 \pm 2$ & \\
\hline \multicolumn{4}{|l|}{$\mathrm{CD} 24$} \\
\hline Positive cases & $15 / 17(88 \%)$ & $21 / 24(88 \%)$ & \\
\hline Negative cases & $2 / 17(12 \%)$ & $3 / 24(12 \%)$ & \\
\hline Mean $\%$ positivity & $70 \pm 7$ & $76 \pm 5$ & \\
\hline \multicolumn{4}{|l|}{$\mathrm{CD} 34$} \\
\hline Positive cases & $11 / 15(73 \%)$ & $6 / 16(38 \%)$ & $0.04\left(\chi^{2}=4.0\right)$ \\
\hline Negative cases & $4 / 15(27 \%)$ & $10 / 16(63 \%)$ & \\
\hline Mean $\%$ positivity & $56 \pm 9$ & $34 \pm 9$ & 0.09 \\
\hline \multicolumn{4}{|l|}{$\mathrm{CD} 40$} \\
\hline Positive cases & $6 / 14(43 \%)$ & $4 / 14(29 \%)$ & \\
\hline Negative cases & $8 / 14(57 \%)$ & $10 / 14(71 \%)$ & \\
\hline Mean $\%$ positivity & $31 \pm 6$ & $21 \pm 7$ & \\
\hline \multicolumn{4}{|l|}{$\mathrm{G}_{0 / 1}$ phase } \\
\hline$<85 \%$ & $2 / 10(20 \%)$ & $6 / 8 \quad(75 \%)$ & \\
\hline$\geq 85 \%$ & $8 / 10(80 \%)$ & $2 / 8 \quad(25 \%)$ & $0.02\left(\chi^{2}=5.4\right)$ \\
\hline \multicolumn{4}{|l|}{ S phase } \\
\hline$<13 \%$ & $7 / 10(70 \%)$ & $2 / 8 \quad(25 \%)$ & \\
\hline$\geq 13 \%$ & $3 / 10(30 \%)$ & $6 / 8 \quad(75 \%)$ & $0.06\left(\chi^{2}=3.6\right)$ \\
\hline \multicolumn{4}{|l|}{$\mathrm{S}+\mathrm{G}_{2} \mathrm{M}$ phase } \\
\hline$<16$ & $9 / 11(82 \%)$ & $3 / 10(30 \%)$ & \\
\hline$\geq 16$. & $2 / 11(18 \%)$ & $7 / 10(70 \%)$ & $0.02\left(\chi^{2}=5.7\right)$ \\
\hline
\end{tabular}

Radiation resistance was defined as $\mathrm{SF}_{2} \geq 0.50$ and $\alpha \leq 0.2$. Continuous covariates were compared using two-sample, two-sided Student's $\mathrm{t}$ tests. Chi-square analyses were used to assess the degree of association between clinical/laboratory parameters and radiation resistance/sensitivity of LPC. $P$ values are given only for significant or nearly significant $(P<0.1)$ differences/associations.

radiation-sensitive cases but only $18 \%$ of radiation-resistant cases had a high proliferative index $\left(\% \mathrm{~S}+\mathrm{G}_{2} \mathrm{M} \geq 16 \%\right)(P$ $=0.02)$ (Table II ). Importantly, a greater fraction of radiationresistant cases were $\mathrm{CD}^{2} 4^{+}(73 \%$ versus $38 \%, P=0.04)$ and the mean CD34 positivity of radiation-resistant B-cell precursor ALL cases was greater than the mean CD34 positivity of radiation-sensitive cases ( $56 \pm 9 \%$ versus $34 \pm 9 \%, P=0.09$ ) (Table II). No differences between radiation-resistant and radiation- sensitive groups were noted relative to expression of CD10, CD19, CD24, or CD40 antigens.

\section{Discussion}

Until recently, very little was known regarding the radiobiologic features of primary leukemic blasts from ALL patients. This paucity of knowledge was caused by historic difficulties in 
cloning freshly isolated primary ALL blasts in vitro. Within the past $6 \mathrm{yr}$, we have refined in vitro colony assay systems to culture primary blasts from T-lineage $\operatorname{ALL}(10,18,28,29)$, as well as B-lineage $\operatorname{ALL}(11,20,27,30,31)$ patients. Subsequent studies using these assay systems provided strong evidence that in vitro clonogenic ALL blasts, referred to as LPC, likely represent counterparts of in vivo clonogenic ALL blasts (10,11, 22, 28 ). In the present study, we used the B-lineage ALL LPC colony assay system to elucidate the radiobiologic features of primary clonogenic blasts from 44 newly diagnosed B-cell precursor ALL patients.

This report extends our earlier work on the radiobiologic features of primary leukemic blasts from ALL patients $(22,25$, 28 ), amplifies our knowledge of the radiobiologic features of human tumor cells (32-46), and provides novel insights into possible associations between cell cycle kinetics, immunophenotype, and radiation sensitivity. The $\alpha$ value, reflecting the initial slope of radiation survival curves constructed according to the linear quadratic model of cell survival, is one predictor of the sensitivity of human tumors to clinical radiation (44). The reported $\alpha$ values for human tumor cells range from 0.2 to 0.6 $\mathrm{Gy}^{-1}(16,32,51)$. The mean $\alpha$ value for B-lineage LPC in the present study is $0.430 \pm 0.093 \mathrm{~Gy}^{-1}$. Notably, 17 of the 44 (39\%) newly diagnosed B-cell precursor ALL patients had $\mathrm{SF}_{2}$ values $\geq 0.50$, which are equivalent to the reported $\mathrm{SF}_{2}$ values for the least radiation-responsive tumors in clinical radiation therapy $(16,42)$. In conjunction with $\alpha$ values $\leq 0.2 \mathrm{~Gy}^{-1}$, our results are consistent with marked intrinsic radiation resistance at the level of clonogenic blasts using the multitarget and linear quadratic models of cell survival. Thus, primary clonogenic blasts from some B-cell precursor ALL patients are clearly among the most radiation resistant human tumor cells reported to date. Early and frequent relapses experienced by Bcell precursor ALL patients within the first $6 \mathrm{mo}$ after $800 \mathrm{cGy}$ single dose or $1,375 \mathrm{cGy}$ hyperfractionated TBI and BMT with only $10-15 \%$ disease-free survival at $2 \mathrm{yr}$ after BMT are in accordance with this conclusion $(2,6,11,13)$. Taken together, these preclinical and clinical observations in B-cell precursor ALL emphasize the need for therapeutic innovation and recommend a reevaluation of the role of TBI in BMT.

The observed radiobiologic heterogeneity among B-cell precursor ALL patients encouraged us to assess the radiobiologic features of primary B-lineage LPC in relation to the more frequently measured diagnostic parameters of age, sex, WBC at diagnosis, cell cycle distribution, proliferation index of leukemic blasts, and immunophenotype. Among these diagnostic parameters, only cell cycle distribution and immunophenotype showed a significant correlation with the intrinsic radiation sensitivity of B-lineage LPC. A trend towards lower $\mathrm{SF}_{2}$ and higher $\alpha$ values was observed for $\mathrm{CD}_{1} 9^{+} \mathrm{CD} 10^{+}$patients, consistent with greater radiation sensitivity. By comparison, an opposite relationship existed between CD34 expression and radiation sensitivity of LPC. LPC from $\mathrm{CD} 19^{+} \mathrm{CD} 34^{+}$patients appeared to be more radiation resistant than LPC from $\mathrm{CD} 19^{+} \mathrm{CD} 34^{-}$patients, as reflected by higher $\mathrm{SF}_{2}$ and lower $\alpha$ values. When patients were divided into three approximately equal groups based on increasing levels of CD34 expression, a clear ordering effect was observed indicating that increased CD34 expression levels are associated with significantly higher radiation resistance at the level of B-lineage LPC. The highest CD34 expression group ( $\geq 75 \%$ positivity) had 1.4-fold higher $\mathrm{SF}_{2}(P=0.05)$ and 2.0 -fold lower $\alpha$ values $(P=0.05)$ than the lowest group ( $<30 \%$ positivity). Importantly, a greater fraction of radiation resistant cases were $\mathrm{CD} 34^{+}(73 \%$ versus $38 \%$, $P=0.04)$ and the mean CD34 positivity of radiation resistant B-cell precursor ALL cases was greater than the mean CD34 positivity of radiation sensitive cases $(56 \pm 9 \%$ versus $34 \pm 9 \%, P$ $=0.09$ ). Taken together, these results prompt the hypothesis that high level CD34 expression is associated with radiation resistance in B-cell precursor ALL. CD34 expression has also been associated with resistance to chemotherapy in myeloid malignancies $(52,53)$ and may be related to poor treatment outcome in B-cell precursor ALL (based on unpublished observations in 1992 by F. M. Uckun, H. Sather, and D. Hammond of the Children's Cancer Study Group).

Human CD34 is a 110-kD lymphohematopoietic progenitor cell associated surface sialomucin antigen that is expressed on normal as well as leukemic progenitor cell populations corresponding to the earliest stages of differentiation (54-58). The gene for CD34 has been mapped to band 1q32 of the long arm of chromosome $1(59,60)$. CD34 cDNA predicts a 373amino acid polypeptide that is a type I integral membrane protein and has no sequence homology to any known protein (58). Notably, $>30 \%$ of the predicted amino acids in the $\mathrm{NH}_{2}$-terminal domain of this antigen are serine or threonine residues and $\mathrm{CD} 34$ antigen is a substrate for protein kinase $\mathrm{C}$ (PKC) $(58,61)$. CD34 antigen can be phosphorylated by PKC in $\mathrm{CD} 34^{+}$leukemic B-cell precursors (58). Fackler et al. have recently shown that multiple serine kinases including glycogen synthase kinase and casein kinase II can phosphorylate CD34 antigen (62). Greaves et al. proposed that the currently undefined function of CD34 is likely to be modulated by signals that stimulate the activation of PKC (58). Intriguingly, more recent studies by Weichselbaum and colleagues demonstrated that ionizing radiation activates PKC in irradiated myeloid cells, including KG-1 cells, which are strongly $\mathrm{CD}^{+} 4^{+}(63)$. Similarly, Uckun et al. reported that in normal and leukemic B-cell precursors, ionizing radiation activates multiple serine kinases including PKC (64). It is therefore likely that CD34 becomes phosphorylated in irradiated cells. The relationship between CD34 positivity and radiation resistance, as presently reported, suggests a possible role for phosphorylated CD34 in intrinsic radiation sensitivity.

Several investigators have noted cell cycle dependent variations in radiation sensitivity of mammalian cells, with the highest levels of sensitivity usually appearing in the $G_{2^{-}}$and $M-$ phases of the cell cycle (65-69). By comparison, quiescent cells and cells in early and mid- $G_{1}$ phase are relatively radiation resistant (65-69). Kimler and Anderson reported that 9L rat brain tumor cells are most resistant to radiation while in G1 phase (70). Weichselbaum explained that the repair of radiation-induced molecular damage may be facilitated if DNA replication is delayed by holding cells in G1 (71). Potmesil and Goldfeder reported that nonproliferating $G_{1}$ confined cells from mouse mammary adenocarcinoma cell lines DBAH and MT2 persist in irradiated tumors of mice and a transition of these nonproliferating cells to the proliferating pool takes place at the start of tumor recurrence (67). In contrast, Wallen et al. reported that quiescent cells from the murine mammary carcinoma cell lines 66 and 67 are significantly more sensitive than proliferating cells from the same cell lines (72). Similarly, Madoc-Jones reported that rat sarcoma cells are most sensitive to ionizing radiation during the $G_{1}$ phase of the cell cycle (73). These reports regarding the radiation sensitivity of quiescent 
$G_{1}$ cells indicate that the most sensitive and resistant phases of the cell cycle may be different for each cell type. Alternatively, not only the exact time of radiation exposure in relation to cell cycle, but also the length of a given cell cycle phase during which the radiation exposure occurred may determine the biological outcome of radiation exposure. In the present study, a high $\mathrm{G}_{0 / 1}$ percentage or low $\mathrm{S}$ phase percentage in leukemic blast populations from newly diagnosed B-cell precursor ALL patients was associated with radiation resistance at the level of LPC. The observed relationship between cell cycle kinetic features and radiation sensitivity recommends agents that can stimulate $S$ phase entry of quiescent ALL blast populations, such as mitogenic cytokines as potentially useful adjuncts to current TBI/BMT regimens for high risk B-cell precursor ALL.

Notably, high WBC at diagnosis was not associated with radiation resistance at the level of LPC. Therefore, the published ability of this factor to predict relapse after TBI and BMT in B-cell precursor ALL (2-9) cannot be explained by the level of radiation resistance.

In summary, we have used in vitro colony assays to study and compare the radiobiologic features of B-lineage LPC from newly diagnosed B-cell precursor ALL patients. Our findings demonstrate a marked interpatient variation in the radiation sensitivity of LPC. We postulate that clonogenic blasts with an inherent and/or acquired resistance to radiation contribute to the high relapse rate after BMT for B-cell precursor ALL. Differences in radiation sensitivity may partially explain the inconsistent responses of B-cell precursor ALL patients to TBI and BMT. The insights acquired from this study should promote sequential comparative analyses of novel radiosensitizing agents, which may ultimately provide more effective conditioning regimens.

\section{Acknowledgments}

This work was supported in part by research grants, including U.S. Public Health Service grants R29 CA-42111, R01 CA-42633, and Childrens Cancer Study Group (CCSG) Chairman's Grant CA-13539-19 from the National Cancer Institute, Department of Human Health Services (DHHS), by Minnesota Medical Foundation, Children's Cancer Research Fund, and a special gift from Louis Kitsis and the Bank of Palm Springs. F. M. Uckun is a Scholar of the Leukemia Society of America. This is publication number 80 from the Tumor Immunology Laboratory, University of Minnesota.

\section{References}

1. Champlin, R., and R. P. Gale. 1989. Acute lymphoblastic leukemia: recent advances in biology and therapy. Blood. 73:2051-2066.

2. Kersey, J. H., D. Weisdorf, M. E. Nesbit, T. W. LeBien, W. G. Woods, P. B. McGlave, T. Kim, D. A. Vallera, A. I. Goldman, B. Bostrom, et al. 1987. Comparison of autologous and allogeneic bone marrow transplantation for treatment of high-risk refractory acute lymphoblastic leukemia. N. Engl. J. Med. 317:461467.

3. Barrett, A. J., M. M. Horowitz, R. P. Gale, J. C. Biggs, B. M. Camitta, K. A Dicke, E. Gluckman, R. A. Good, R. H. Herzig, M. B. Lee, et al. 1989. Marrow transplantation for acute lymphoblastic leukemia: factors affecting relapse and survival. Blood. 74:862-871.

4. Doney, K., C. D. Buckner, K. J. Kopecky, J. E. Sanders, F. R. Appelbaum, R. Clift, K. Sullivan, R. Witherspoon, R. Storb, and E. D. Thomas. 1987. Marrow transplantation for patients with acute lymphoblastic leukemia in first marrow remission. Bone Marrow Transplant. 2:355-363.

5. Dicke, K. A., and G. F. Spitzer. 1986. Clinical studies of autografting in acute lymphoblastic leukemia. Clin. Haematol. 15:85-103.

6. Ramsay, N., T. LeBien, M. Nesbit, P. McGlave, D. Weisdorf, P. Kenyon, D. Hurd, A. Goldman, T. Kim, and J. Kersey. 1985. Autologous bone marrow transplantation for patients with acute lymphoblastic leukemia in second or sub- sequent remission: results of bone marrow treated with monoclonal antibodies BA-1, BA-2, and BA-3 plus complement. Blood. 66:508-513.

7. Coccia, P. F., S. E. Strandjord, P. I. Warkentin, N. V. Cheung, E. M. Gordon, L. J. Novak, D. C. Shina, and R. H. Herzig. 1982. High dose cytosine arabinoside and fractionated total body irradiation: an improved preparative regimen for bone marrow transplantation of children with acute lymphoblastic leukemia in remission. Blood. 71:888-893.

8. Santos, G., and H. Kaizer. 1982. Bone marrow transplantation in acute leukemia. Semin. Hematol. 19:227-239.

9. O'Reilly, R. J. 1983. Allogeneic bone marrow transplantation: current status and future directions. Blood. 62:941-964.

10. Uckun, F. M., J. H. Kersey, D. A. Vallera, J. A. Ledbetter, D. Weisdorf, D. E. Myers, R. Haake, and N. K. C. Ramsay. 1990. Autologous bone marrow transplantation in high risk remission T-lineage acute lymphoblastic leukemia using immunotoxins plus 4-hydroperoxycyclophosphamide for marrow purging. Blood. 76:1723-1733.

11. Uckun, F. M., J. H. Kersey, R. Haake, D. Weisdorf, and N. K. C. Ramsay. 1992. Autologous bone marrow transplantation in high-risk remission $\beta$-lineage acute lymphoblastic leukemia using a cocktail of three monoclonal antibodies (BA-1 /CD24, BA-2/CD9, and BA-3/CD10) plus complement and 4-hydroperoxycyclophosphamide for ex vivo bone marrow purging. Blood. 79:1094-1 104.

12. Chao, N. J., S. J. Forman, G. M. Schmidt, D. S. Snyder, M. D. Amylon, P. N. Konrad, A. P. Nademanee, M. R. O'Donnell, P. M. Parker, A. S. Stein, et al. 1991. Allogeneic bone marrow transplantation for high-risk acute lymphoblastic leukemia during first complete remission. Blood. 78:1923-1927.

13. Uckun, F. M., J. H. Kersey, R. Haake, D. Weisdorf, M. E. Nesbit, and N. K. C. Ramsay. 1992. Pretransplant leukemic progenitor cell burden as a predictor of relapse after autologous bone marrow transplantation for high risk remission acute lymphoblastic leukemia. Blood. 80:1499 (Abstr.)

14. Albright, N. 1987. Computer programs for the analysis of cellular survival data. Radiat. Res. 112:331-340.

15. Hall, E. J. 1972. Cell survival curves. In Radiobiology for the Radiobiologists. Harper \& Row, Philadelphia. 31-62.

16. Steel, G. G., T. J. McMillan, and J. H. Peacock. 1989. The radiobiology of human cells and tissues. In vitro radiosensitivity. The picture has changed in the 1980s. Int. J. Radiat. Biol. 56:525-537.

17. Uckun, F. M., A. Muraguchi, J. A. Ledbetter, T. Kishimoto, R. T. O'Brien, J. S. Roloff, K. Gajl-Peczalska, A. Provisor, and B. Koller. 1989. Biphenotypic leukemic lymphocyte precursors in CD2+CD19+ acute lymphoblastic leukemia and their putative normal counterparts in human fetal hematopoietic tissues. Blood. 73:1000-1015.

18. Uckun, F. M., D. E. Myers, J. A. Ledbetter, S. E. Swaim, K. J. Gajl-Peczalska, and D. A. Vallera. 1988. Use of colony assays and leukemic anti-T-cell immunotoxins to elucidate the immunobiological features of leukemic progenitor cells in T-lineage acute lymphoblastic leukemia. J. Immunol. 140:2103-2111.

19. Uckun, F. M., D. E. Myers, W. Jaszcz, S. Haissig, K. Gajl-Peczalska, and J. A. Ledbetter. 1990. Temporal association of CD40 antigen expression with discrete stages of human B-cell ontogeny and the efficacy of anti-CD40 immunotoxins against clonogenic B-lineage acute lymphoblastic leukemia as well as B-lineage non-Hodgkin's lymphoma cells. Blood. 76:2449-2456.

20. Uckun, F. M., and J. A. Ledbetter. 1988. Immunobiologic differences between normal and leukemic human B-cell precursors. Proc. Natl. Acad. Sci. USA. 85:8603-8607.

21. Crissman, H. A., Z. Darzynkiewicz, R. A. Tobey, and J. A. Steinkamp. 1985. Correlated measurements of DNA, RNA and protein in individual cells by flow cytometry. Science (Wash. DC). 228:1321-1324.

22. Uckun, F. M., N. K. C. Ramsay, K. G. Waddick, W. Jaszcz, M. ChandanLanglie, V. Obuz, R. Haake, K. Gajl-Peczalska, J. H. Kersey, and C. W. Song. 1991. In vitro and in vivo radiation resistance associated with CD3 surface antigen expression in T-lineage acute lymphoblastic leukemia. Blood. 78:2945-2955.

23. Uckun, F. M., S. Gillis, L. Souza, and C. W. Song. 1989. Effects of recombinant human growth factors on radiation survival of bone marrow progenitor cells. Int. J. Radiat. Oncol. Biol. Phys. 16:415-435.

24. Uckun, F. M., J. B. Mitchell, V. Obuz, H. J. Chae, K. Waddick, N. Friedman, L. Oubaha, W. S. Min, and C. W. Song. 1991. Radiation sensitivity of human B-lineage lymphoid precursor cells. Int. J. Radiat. Oncol. Biol. Phys. 21:1553-1560.

25. Uckun, F. M., and C. W. Song. 1988. Radiobiological features of leukemic progenitor cells in acute lymphoblastic leukemia. Cancer Res. 48:5788-5795.

26. Uckun, F. M., and N. A. Heerema. 1990. Use of leukemic progenitor cell assays for a more detailed analysis of the cytogenetic changes occurring during clonal evolution in acute lymphoblastic leukemia. Leuk. \& Lymphoma. 2:1-16.

27. Uckun, F. M., A. S. Fauci, C. W. Song, S. R. Mehta, N. A. Heerema, K. J. Gajl-Peczalska, and J. L. Ambrus. 1987. B-cell growth factor receptor expression and B cell growth factor response of leukemic B-cell precursors and B lineage lymphoid progenitor cells. Blood. 70:1020-1034.

28. Uckun, F. M., C. W. Song, M. Nesbit, J. H. Kersey, and N. K. C. Ramsay. 1992. Immunophenotype predicts radiation resistance in T-lineage acute lympho- 
blastic leukemia and T-lineage non-Hodgkin's lymphoma. Int. J. Radiat. Oncol. Biol. Phys. 24:705-712.

29. Uckun, F. M., K. J. Gajl-Peczalska, D. E. Myers, N. K. C. Ramsay, J. H. Kersey, M. Colvin, and D. A. Vallera. 1987. Marrow purging in autologous bone marrow transplantation for T-lineage acute lymphoblastic leukemia: efficacy of ex vivo treatment with immunotoxins and 4-hydroperoxycyclophosphamide against fresh leukemic marrow progenitor cells. Blood. 69:361-366.

30. Uckun, F. M., K. J. Gajl-Peczalska, J. H. Kersey, L. L. Houston, and D. A. Vallera. 1986. Use of a novel colony assay to evaluate the cytotoxicity of an immunotoxin containing pokeweed antiviral protein against blast progenitor cells freshly obtained from patients with common B-lineage acute lymphoblastic leukemia. J. Exp. Med. 163:347-368.

31. Uckun, F. M., J. H. Kersey, K. J. Gajl-Peczalska, N. A. Heerema, A. J. Provisor, D. Haag, G. Gilchrist, C. W. Song, D. C. Arthur, J. Roloff, et al. 1987 Heterogeneity of cultured leukemic lymphoid progenitor cells from B-cell precursor acute lymphoblastic leukemia patients. J. Clin. Invest. 80:639-646.

32. Weichselbaum, R. R., and J. B. Little. 1983. X-ray sensitivity and repair in human tumour cells. In The Biological Basis of Radiotherapy. W. Steel, M. Adams, and J. Peckham, editors. Elsevier Science Publishers B. V., Amsterdam. 113-121.

33. Weichselbaum, R. R., J. Rotmensch, S. Ahmed-Swan, and M. A. Beckett. 1989. Radiobiological characterization of 53 human tumor cell lines. Int. J. Radiat. Biol. 56:553-560.

34. Peckham, M. J. 1983. The Biological Basis of Radiotherapy G. G. Steele et al., editors. Elsevier Science Publishers, 1-50.

35. Weichselbaum, R. R., W. Dahlberg, and J. B. Little. 1985. Inherently radioresistant cells exist in some human tumors. Proc. Natl. Acad. Sci. USA 82:4732-4735

36. Weichselbaum, R. R. 1986. Radioresistant and repair proficient cells may determine radiocurability in human tumors. Int. J. Radiat. Oncol. 12:637-639.

37. Weichselbaum, R. R., J. S. Greenberger, A. Karpas, A. Schmidt, and J. B. Little. 1981. Radiosensitivity of human hemapoietic cell lines of distinguishable biochemical and physiological stages of differentiation. Radiology. 139:485-487.

38. Weichselbaum, R. R., J. S. Greenberger, A. Schmidt, A. Karpas, W. C. Moloney, and J. B. Little. 1981. In vitro radiosensitivity of human leukemia cell lines. Radiology. 139:485-487.

39. Steel, G. G., and V. D. Courtenay. 1983. The radiobiology of human tumour cells. In The Biological Basis of Radiotherapy. W. Steel, M. Adams, and J. Peckham, editors. Elsevier Science Publishers B. V., Amsterdam. 123-137.

40. Kimler, B. F., C. H. Park, D. Yakar, and R. M. Mies. 1985. Radiation response of human normal and leukemia hemopoietic cells assayed by in vitro colony formation. Int. J. Radiat. Oncol. Biol. Phys. 11:809-816.

41. Rofstad, E. K., A. Wahl, and T. Brustad. 1987. Radiation sensitivity in vitro of cells isolated from human tumor surgical specimens. Cancer Res. 47:106110.

42. Fertil, B., and E. P. Malaise. 1985. Intrinsic radiosensitivity of human cell lines is correlated with radioresponsiveness of human tumors: analysis of 101 published curves. Int. J. Radiat. Oncol. Biol. Phys. 11:1699-1707.

43. Fertil, B., and E. P. Malaise. 1981. Inherent cellular radiosensitivity as a basic concept for human tumor radiotherapy. Int. J. Radiat. Oncol. Biol. Phys. 7:621-629.

44. Malaise, E. P., B. Fertil, P. J. Deschavanne, N. Chavaudra, and W. A. Brock. 1987. Initial slope of radiation survival curves is characteristic of the origin of primary and established cultures of human tumor cells and fibroblasts. Radiat. Res. 111:319-333.

45. Fitzgerald, T. J., J. McKenna, K. Kase, C. Daugherty, L. Rothstein, and J. S. Greenberger. 1986. Effect of X-irradiation dose rate on the clonogenic survival of human and experimental animal hemotopoietic tumor cell lines: evidence for heterogeneity. Int. J. Radiat. Oncol. Biol. Phys. 12:69-73.

46. Prasad, K. N. 1984. Factors affecting radiosensitivity. In Handbook of Radiobiology. K. N. Prasad, editor. CRC Press, Inc., Boca Raton, FL. 247-255.

47. Uckun, F. M., and C. W. Song. 1989. Radiobiological features of human pluripotent bone marrow progenitor cells (CFU-GEMM). Int. J. Radiat. Oncol. Biol. Phys. 17:1021-1025.

48. Song, C. W., T. H. Kim, F. M. Khan, J. H. Kersey, and S. H. Levitt. 1981. Radiobiological basis of total body irradiation with different dose rate and fractionation: Repair capacity of hemopoietic cells. Int. J. Radiat. Oncol. Biol. Phys. $7: 1695-1701$.

49. UNSCEAR. 1988. Sources, Effects and Risks of Ionizing Radiation. United Nations Scientific Committee on the Effects of Atomic Radiation, Report to the General Assembly (with Annexes). United Nations Sales Publication E.88.IX.7. United Nations, NY.

50. Fitzgerald, T. J., M. McKenna, L. Rothstein, C. Daugherty, K. Kase, and J. S. Greenberger. 1986. Radiosensitivity of human bone marrow granulocyte- macrophage progenitor cells and stromal colony forming cells: effect of dose rate. Radiat. Res. 107:205-215.

51. Deschavanne, P. J., and E. P. Malaise. 1989. The relevance of $\alpha / \beta$ ratios determined in vitro for human cell lines to the understanding of in vivo values. Int. J. Radiat. Biol. 56:539-542.

52. Geller, R. B., M. Zahurak, C. A. Hurwitz, P. J. Burke, S. Piantadosi, and C. I. Civin. 1990. Prognostic importance of immunophenotyping in adults with acute myelocytic leukemia: the significance of the stem-cell glycoprotein CD34 (MY10). Br. J. Haematol. 76:340-347.

53. Guinot, M., G. F. Sanz, A. Sempere, M. J. Arilla, I. Arque, F. Gomis, and M. A. Sanz. 1991. Prognostic value of CD34 expression in de novo acute myeloblastic leukemia. Br. J. Haematol. 79:533-534.

54. Uckun, F. M. 1990. Regulation of human B-cell ontogeny (review). Blood. 76:1908-1923.

55. Vaughan, W. P., C. I. Civin, D. D. Weisenburger, J. E. Karp, M. L. Graham, W. G. Sanger, H. L. Grierson, S. S. Joshi, and P. J. Burke. 1988. Acute leukemia expressing the normal human hematopoietic stem cell membrane glycoprotein CD34 (MY10). Leukemia (Basingstoke). 2:661-666.

56. Azuma, E., M. Umemoto, M. Kubo, Y. Ohta, S. L. Zhang, Y. Komada M. Ito, and M. Sakurai. 1991. CD34 antigen expression in children with Philadelphia chromosome-positive acute lymphoblastic leukemia. Cancer (Phila.) 67:1565-1569.

57. Greaves, M. F., J. Brown, H. V. Molgaard, N. K. Spurr, D. Robertson, D. Delia, and D. R. Sutherland. 1992. Molecular features of CD34: Hemopoietic progenitor cell-associated molecule. Leukemia (Basingstoke). 6:31-36.

58. Simmons, D. L., A. B. Satterthwaite, D. G. Tenen, and B. Seed. 1992 Molecular cloning of a cDNA encoding CD34, a sialomucin of human hematopoietic stein cells. J. Immunol. 148:267-271.

59. Tenen, D. G., A. B. Satterthwaite, R. Borson, D. Simmons, R. L. Eddy, and T. B. Shows. 1990. Chromosome 1 localization of the gene for CD34, surface antigen of human stem cells. Cytogenet. Cell Genet. 53:55-57.

60. Howell, S. M., H. V. Molgaard, M. F. Greaves, and N. K. Spurr. 1991. Localisation of the gene coding for the haemopoietic stem cell antigen CD34 to chromosome 1q32. Hum. Genet. 87:625-627.

61. Fackler, M. J., C. I. Civin, D. R. Sutherland, M. A. Baker, and W. S. May. 1990. Activated protein kinase $C$ directly phosphorylates the CD34 antigen on hematopoietic cells. J. Biol. Chem. 265:11056-11061.

62. Fackler, M. J., P. T. Tauzon, J. A. Traugh, B. F. Khatra, B. T. Smith, and W. S. May. 1991. CD34 antigen appears to be phosphorylated in KG1 cells by multiple serine protein kinases. Blood. 76:91a.

63. Brach, M. A., R. Hass, M. L. Sherman, H. Gunji, R. Weichselbaum, and D. Kufe. 1991. Ionizing radiation induces expression and binding activity of the nuclear factor $\kappa$ B. J. Clin. Invest. 88:691-695.

64. Uckun, F. M., L. Tuel-Ahlgren, G. Schieven, C. H. Park, I. Dibirdik, R. Smith, D. E. Myers, and C. W. Song. 1992. Tyrosine-phosphorylation is a mandatory proximal step in radiation-induced activation of protein kinase $\mathrm{C}$ signaling pathway in human B-lymphocyte precursors. Proc. Natl. Acad. Sci. USA. In press.

65. Potmesil, M., and A. Goldfeder. 1980. Cell kinetics of irradiated experimental tumors: cell transition from the non-proliferating to the proliferating pool. Cell Tissue Kinet. 13:563-570.

66. Mendonca, M. S., A. Rodriguez, and E. L. Alpen. 1989. Quiescence in 9L cells and correlation with radiosensitivity and PLD repair. Radiat. Res. 117:433447.

67. Potmesil, M., D. Ludwig, and A. Goldfeder. 1975. Cell kinetics of irradiated experimental tumors: relationship between the proliferating and the nonproliferating pool. Cell Tissue Kinet. 8:369-385.

68. Barendsen, G. W., H. Roelse, A. F. Hermens, H. T. Madhuizen, H. A. van Peperzeel, and D. H. Rutgers. 1973. Clonogenic capacity of proliferating and nonproliferating cells of a transplantable rat rhabdomyosarcoma in relation to its radiosensitivity. J. Natl. Cancer Inst. (Bethesda). 51:1521-1526.

69. Little, J. B. 1969. Repair of sub-lethal and potentially lethal radiation damage in plateau phase cultures of human cells. Nature (Lond.). 224:804-806.

70. Kimler, B. F., and S. D. Henderson. 1992. Cyclic responses of cultured 9L cells to radiation. Radiat. Res. 91:155-168.

71. Weichselbaum, R. 1986. Radioresistant and repair proficient cells may determine radiocurability in human tumors. Int. J. Radiat. Oncol. Biol. Phys. 12:637-639.

72. Wallen, A., D. N. Ridinger, and Dethlefsen. 1985. Heterogeneity of x-ray cytotoxicity in proliferating and quiescent murine mammary carcinoma cells. Cancer Res. 45:3064-3069.

73. Madoc-Jones, H. 1964. Variations in radiosensitivity of a mammalian cell line with phase of the growth cycle. Nature (Lond.). 8:983-984. 